\title{
O PROCESSO DE CONSTRUÇÃO DOS SABERES DOCENTES DE PROFESSORES DE EDUCAÇÃO FíSICA ATUANTES EM ESCOLAS DE EDUCAÇÃO ESPECIAL
}

\author{
V. J. Casarotto e H. N. Krug
Universidade Federal de Santa Maria
hnkrug@bol.com.br \\ Submetido em 01/10/2014 - Aceito em 19/11/2016 \\ DOI: $10.15628 /$ holos.2016.2468
}

\section{RESUMO}

Esta investigação objetivou analisar o processo de construção dos saberes docentes de professores de Educação Física atuantes em escolas de Educação Especial. O estudo caracterizou-se como qualitativo descritivo e estudo de casos múltiplos. O instrumento para a coleta de informações foi uma entrevista semiestruturada, realizada com três professores de Educação Física. A interpretação das informações foi à análise de conteúdo. Concluiu-se que: a) A formação inicial dos professores estudados não ofereceu subsídios suficientes para a atuação em escolas de Educação Especial; b) A prática diária nas aulas contribuiu para a construção dos saberes docentes; c) Apenas um professor investe na sua formação continuada; e, d) Os professores aprenderam a docência com os alunos com deficiência a partir de seus saberes experienciais.

PALAVRAS-CHAVE: formação de professores, educação física, educação especial, saberes docentes.

\section{THE PROCESS OF CONSTRUCTION OF THE KNOWLEDGE TEACHING OF PHYSICAL EDUCATION TEACHERS ACTING IN SCHOOLS SPECIAL EDUCATION}

\begin{abstract}
This investigation aimed to analyze the process of construction of knowledge teaching of physical education teachers acting in schools of Special Education. The study was characterized with qualitative descriptive and multiple case study. The instrument for the data collection information was a semi-structured interview, realized with three Physical Education teachers. The interpretation of information was content
\end{abstract}

analysis. Concluded that: a) The initial formation of teachers studied did not offer sufficient subsidies for the actuation in schools of Special Education; b) The daily practice in the classroom contributed for the construction of teaching knowledge; c) Only one teacher invests in their continued formation; and, d) The teachers learned the teaching with the students with deficiency from of their experiential knowledge

KEYWORDS: teacher formation, physical education, special education, teachers knowledge.. 


\section{INTRODUÇÃO}

A Educação Física está presente desde os primórdios da humanidade, onde o ser humano sentia a necessidade de movimentar-se, sendo para o seu prazer ou mesmo para a sua sobrevivência. Os exercícios físicos estão presentes desde a Pré-História, perpassando pela Antiguidade, Idade Média, Idade Moderna e Idade Contemporânea (RAMOS, 1982). A Educação Física como área da ciência construiu a sua trajetória, buscando, perante a sociedade, a sua legitimidade para a inserção nas instituições escolares. Nessa trajetória, assumiu a função de componente curricular obrigatório para a Educação Básica, visto que, de acordo com a Lei de Diretrizes e Bases n. 9.394/96 (BRASIL, 1996), especificamente o seu Artigo 26은iso 3ㅇ, coloca que a partir dessa Lei, a Educação Física passaria a ser integrada à proposta pedagógica da escola, sendo sua prática facultativa em alguns casos específicos, sendo estes: I - que cumpra jornada de trabalho igual ou superior a seis horas; II - maior de trinta anos de idade; III - que estiver prestando serviço militar inicial ou que, em situação similar, estiver obrigado à prática da educação física; IV - amparado pelo Decreto-Lei n. 1.044, de 21 de outubro de 1969; V (VETADO) e VI - que tenha prole.

Neste sentido, segundo Betti e Zuliani (2002), a Educação Física na escola assume a função de:

\footnotetext{
[...] introduzir e integrar o aluno na cultura corporal de movimento, formando o cidadão que vai produzi-la, reproduzi-la e transformá-la, instrumentalizando-o para usufruir do jogo, do esporte, das atividades rítmicas, da dança, das ginásticas e práticas de aptidão física, em benefício da qualidade de vida. A integração que possibilitará o usufruto da cultura corporal de movimento há de ser plena - é afetiva, social, cognitiva e motora. Vale dizer, é a integração de sua personalidade (BETTI; ZULIANI, 2002, p.75).
}

Assim, a principal característica da Educação Física é o movimento, e, isso é o que a diferencia das demais disciplinas do currículo escolar. Caparroz (2005, p.57) destaca que "a ginástica, o jogo, o esporte e a dança são os seus elementos, portanto, fazer Educação Física é relacionar o movimento com a inteligência". Para tanto, exige do professor compromisso, a criatividade nas aulas, tornando-as cada vez mais atrativas para os alunos, valorizando cada vez mais esse espaço.

Entretanto, para Moreira (2004), isto não quer dizer que a Educação Física seja mais importante que as outras disciplinas do currículo escolar, mas demonstra que essa deveria ter o mesmo grau de importância das demais, pois também faz parte do processo de formação dos alunos. Nesse sentido, a Educação Física deve proporcionar aos alunos um desenvolvimento pleno, onde seja possível o aprimorando das capacidades individuais e coletivas em todos os ambientes de ensino. $O$ diferencial no resultado final, no caso o aprendizado dos alunos, surge a partir do interesse pessoal de cada um, assim como da maneira como o professor conduz a aula.

Partindo destes pressupostos, vislumbramos um ambiente adequado que colabora com o aprendizado dos alunos e, nesse caso, as escolas de Educação Especial são de extrema importância no desenvolvimento de crianças, jovens e adultos com deficiência, pois, propiciam atendimento especializado, diferente das escolas regulares, que, em sua maioria, apresentam dificuldades para atender, especificamente, esses alunos, em função da falta de qualificação dos professores que não recebem suporte teórico-metodológico tal ação, assim como a falta de materiais didáticos e espaço físico, enfim, geralmente a infraestrutura das escolas não propiciam acessibilidade para esse público específico. 
Entretanto, é importante recordarmos que a formação do professor de Educação Física, implica num processo contínuo, o qual precisa ir além da sua formação inicial principalmente quando esse lecionar em escolas de Educação Especial.

Para García (1999) a formação de professores é uma área de conhecimentos e investigações, na qual se estudam propostas em que os professores adquirem conhecimentos, competências, que lhes permitem interferir profissionalmente no desenvolvimento de seu ensino em busca da qualidade educativa. Coloca que a formação de professores é dividida em dois momentos: a formação inicial e a formação continuada.

Relativamente sobre a formação inicial dos professores de Educação Física, Carreiro da Costa (1994, p.27) observa que a mesma corresponde "ao período durante o qual o futuro professor adquire conhecimentos científicos e pedagógicos e as competências necessárias para enfrentar adequadamente a carreira docente".

Neste sentido, consideramos fundamental compreender como se realizou a formação inicial de professores de Educação Física que atuam em escolas de Educação Especial, pois, a realidade tem mostrado que, na maioria das vezes, essa formação é pouco significativa para proporcionar competências que sustentam a prática docente com alunos com deficiência. Alguns estudos recentes (TAVARES; KRUG, 2003; FLORES, 2012) destacam que a formação inicial traz uma contribuição pouco significativa para preparar o futuro professor para atuar em escolas de Educação Especial. Marques (2011) corrobora com essa ideia ao dizer que o professor quando conclui sua formação inicial não está totalmente preparado para ensinar, não domina o conteúdo, não conhece metodologias eficazes, pois ele ainda não possui experiência necessária para a prática docente.

Entretanto, Flores (2012, p.3) coloca que é na "formação inicial que começamos a nos organizar e adquirir os conhecimentos específicos de nossa atuação profissional, compreendendo que esta etapa é apenas o início de uma formação permanente".

Neste contexto, entendemos que é importante debater aspectos referentes a este momento para melhor preparar e qualificar a formação profissional do futuro professor principalmente pelas 'exigências' (características individuais e coletivas dos educandos) na preparação e execução das aulas para alunos com deficiência.

Ao lecionar em escolas de Educação Especial é importante que o professor de Educação Física possua conhecimentos, e, preferencialmente, tenha experiências com alunos com deficiência. Porém, é necessário que a formação inicial tenha propiciado conhecimentos teóricopráticos suficientes para suprir as necessidades formativas para a sua atuação nesse contexto específico.

Desta maneira, considerando as premissas explicitadas, partimos do pressuposto de que a formação inicial de professores de Educação Física, ao longo dos anos, não tenha sido suficiente para embasar a atuação desses profissionais em escolas de Educação Especial, refletindo assim, em uma prática pedagógica ineficiente. A partir disso, acreditamos ser relevante que os professores de Educação Física tenham acesso à formação continuada específica para melhorar a sua prática pedagógica.

Silva (2000, p.21) define formação continuada como "o conjunto de atividades que se realizam após a formação inicial, que têm como objetivo desenvolver os conhecimentos e as competências dos professores, tendo em vista o seu aperfeiçoamento profissional".

Assim, a formação continuada pode acontecer através do estudo, da discussão, da confrontação das experiências e de reflexão sobre a prática pedagógica dos professores, desde que, os professores busquem qualificarem-se. Esse conjunto de fatores associados pode melhorar consideravelmente a qualidade do ensino para os alunos com deficiência. 
Todavia, concordamos com Candau (1996) ao sinalizar que a formação continuada não pode ser concebida como um meio de acumulação (de cursos, palestras, seminários, etc., de conhecimentos ou técnicas), mas, sim, através de um trabalho de reflexividade crítica sobre as práticas e de (re)construção permanente de uma identidade pessoal e profissional, em interação mútua.

Logo, a formação inicial e continuada são elementos fundamentais na prática pedagógica, para tanto, a experiência vivenciada e a troca de saberes entre os professores, são essenciais para o crescimento profissional e pessoal dos docentes.

De acordo com Tardif (2002), embora os professores utilizem diferentes saberes, essa utilização se dá em função do seu trabalho e das situações, condicionamentos e recursos ligados a esse trabalho. As relações dos professores com os saberes nunca são relações estritamente cognitivas, são relações mediadas pelo trabalho que lhes fornecem princípios para enfrentar e solucionar situações cotidianas.

Assim, direcionamos este estudo (in)diretamente para os saberes docentes construídos, utilizados e reconstruídos por professores de Educação Física atuantes em escolas de Educação Especial da cidade de Santa Maria-RS.

Com este propósito, consideramos necessário citar Bernardi e Krug (2008) que destacam que o professor de Educação Física em sua docência precisa repensar toda a sua formação profissional, buscando não aplicar teorias, nem simplesmente adaptá-las, mas, de certa forma, desconstruir modelos hegemônicos de atuação e criar ao lado do aluno formas, e métodos, em que ambos sejam sujeitos nesse processo.

Neste sentido, afirmamos que o professor precisa ter propriedade dos saberes que constituem o seu fazer docente, tendo capacidade de articulá-los conforme a realidade específica de seu trabalho cotidiano.

Tardif (2002) define os saberes docentes como a confluência de vários saberes provenientes de diferentes fontes, saberes oriundos da sociedade, da instituição escolar, dos atores educacionais, das universidades, etc. Ressalta que todos esses saberes, são adquiridos pelo professor durante a formação profissional. É por meio deles que o professor cria subsídios para constituir-se professor, em determinado espaço e tempo, tendo ampla relação com o seu local de trabalho.

O autor diz que os saberes dos professores é algo muito mais complexo do que se pode imaginar ou numerar. Esses saberes são provenientes de uma temporalidade, onde simples acontecimentos se responsabilizam pela construção do caráter docente. Assim, o autor os classifica em quatro tipos: 1) Saberes de formação profissional - são os conjuntos de saberes transmitidos pelas instituições de formação de professores. Num primeiro momento esses saberes parecem ser apenas transmitidos pelas ciências da educação, contudo, as relações desse saber com o conhecimento oriundo da prática educacional, constituem o saber pedagógico através da reflexão sobre as práticas educativas; 2) Saberes disciplinares - são adquiridos na formação inicial e continuada, sendo produzidos, definidos e selecionados dentro das universidades. Os saberes das disciplinas emergem da tradição cultural e dos grupos sociais produtores de saberes; 3) Saberes curriculares - correspondem aos discursos, objetivos, conteúdos e métodos a partir dos quais a instituição escolar categoriza e apresenta os saberes sociais por ela definidos e selecionados como modelos da cultura erudita e de formação para a cultura erudita; e, 4) Saberes experienciais ou práticos - correspondem aos saberes próprios do professor e da sua vida educacional, sendo que incorpora a experiência individual e coletiva.

Desta forma, os saberes docentes são objetivados na prática cotidiana do professor, através da relação que consegue estabelecer com os diversos saberes, com os quais, tem contato 
em diferentes momentos durante a sua formação, com conhecimentos científicos e concepções que embasam a sua ação, mediados pelos programas da escola e pelo seu dia a dia, além da sua relação com seus alunos e com os demais colegas de profissão, na forma como organiza suas aulas e seu ambiente pedagógico. Assim, torna-se importante conhecê-los e analisá-los (BERNARDI; KRUG, 2008).

Considerando o contexto apresentado até então, chegamos a seguinte questão problemática norteadora desta investigação: como os professores de Educação Física atuantes em escolas de Educação Especial constroem os seus saberes docentes?

A partir da questão problemática estruturamos o objetivo deste estudo como sendo: analisar o processo de construção dos saberes docente de professores de Educação Física atuantes em escolas de Educação Especial.

Como justificativa para a realização da pesquisa consideramos importante recordar que, nos últimos anos, foram produzidas mudanças significativas na educação formal, principalmente referente ao acesso e permanência de alunos com deficiência em escolas regulares. A partir de então, é crescente a preocupação com a melhora da qualidade da educação e, principalmente com a formação inicial e continuada de professores. Dessa forma, é extremamente importante que o professor compreenda as diferentes necessidades de seus alunos, procurando adquirir ferramentas suficientes que possibilitem aulas que atendam as características dos alunos. Destacamos também, a escassez de estudos ligados aos saberes docentes em Educação Física, particularmente os saberes docentes relacionados às escolas de Educação Especial.

\section{PROCEDIMENTOS METODOLÓGICOS}

Caracterizamos este estudo como qualitativo descritivo e estudo de casos múltiplos.

Segundo Cauduro (2004) a pesquisa qualitativa é aquela que procura explorar a fundo conceitos, atitudes, comportamentos, opiniões e atributos do universo pesquisado, avaliando aspectos emocionais e intencionais, implícitos nas opiniões dos sujeitos da pesquisa, empregando entrevistas individuais, técnicas de discussão em grupo, observações e estudo documental.

De acordo com Gil (2010) a pesquisa descritiva tem como objetivo primordial a descrição das características de determinada população ou fenômeno ou o estabelecimento de relações entre variáveis. Para esse autor o estudo de casos múltiplos são aqueles em que o pesquisador estuda conjuntamente mais de um caso para investigar determinado fenômeno. Os casos múltiplos investigados nesta pesquisa foram duas escolas de Educação Especial da cidade de Santa Maria-RS.

O instrumento utilizado foi uma entrevista semiestruturada, sendo que as informações coletadas foram analisadas por meio da análise de conteúdo (BARDIN, 1977).

Ainda Bardin (1977, p.117) ao abordar sobre categorias de análise a conceitua como sendo "rubricas ou classes que reúnem um grupo de elementos (unidades de registro) em razão de características comuns". As categorias escolhidas a priori foram: formação inicial, formação continuada e saberes docentes. A análise e discussão das informações coletadas foram orientadas e explicitadas a partir dessas categorias.

Destacamos que os sujeitos selecionados para participar da pesquisa foram professores de Educação Física, tendo os seguintes critérios de inclusão: 1) Ser professor de Educação Física efetivo da escola; e, 2) Ter mais de dois anos de atuação com alunos com deficiência. Os critérios de exclusão foram: 1) Ser estagiário ou professor contratado da escola; e, 2) Ter menos de dois anos de atuação com alunos com deficiência. 
Quanto aos aspectos éticos vinculados às pesquisas científicas, destacamos que os envolvidos assinaram o Termo de Consentimento Livre e Esclarecido e suas identidades forma preservadas.

As escolas de Educação Especial foram as seguintes:

1) Escola A - Localizada na Vila Lorenzi, região sul da cidade. Possui ensino fundamental e médio e é organizada por ciclos. Apresenta uma proposta de educação bilíngue para surdos, sendo a língua de sinais a primeira língua e a língua portuguesa, na modalidade escrita, como segunda. Esse ambiente linguístico tem como propósito promover o desenvolvimento do cidadão analítico, reflexivo, crítico, capaz de transitar emocional e intelectualmente pela sociedade. Dois professores da escola participaram da pesquisa.

O professor $A_{1}$ tem 54 anos, se formou em 1983 na Universidade Federal de Santa Maria (UFSM). Possui pós-graduação pela Universidade Metodista de Piracicaba em 1990. Está a 28 anos atuando como professor de Educação Física, sendo que nessa escola de Educação Especial leciona há um ano, mas sempre trabalhou com alunos com deficiência de forma individual, ministra 20 horas/aula nessa escola semanalmente.

A professora $A_{2}$ tem 37 anos, se formou em 1999 na UFSM. Possui pós-graduação pela Universidade de Santa Cruz do Sul em 2005. Atua como professora há 11 anos, e nessa escola de Educação Especial há oito anos, minitrando 40 horas/aulas semanais.

2) Escola B - Está localizada na região central da mesma cidade e possui turmas que são divididas através das habilidades, potencialidades de cada aluno. A escola é uma instituição com fins filantrópicos, que procura prestar assistência clínica e pedagógica a alunos com deficiência. Essa escola possui uma professora incluída no estudo.

A professora $B_{1}$ possui 47 anos, se formou em 1987 no CEFD/UFSM. Não possui pósgraduação, e atua há 25 anos como professora de Educação Física nessa escola.

\section{ANÁLISE E DISCUSSÃO DAS INFORMAÇÕES COLETADAS}

A análise e discussão das informações coletadas foram orientadas e explicitadas a partir das categorias de análise citadas anteriormente.

\subsection{Formação Inicial}

A formação inicial é sem dúvida um período essencial e indispensável para que os futuros professores consigam na prática educativa desenvolver metodologias de ensino capazes de suprir as necessidades da realidade de ensino na qual estarão inseridos (CARREIRO DA COSTA, 1994).

Assim, quando perguntados sobre 'o interesse na atuação profissional com alunos com deficiência', o professor $A_{1}$ falou que desde a formação inicial sempre demostrou interesse na área de Educação Especial. A professora $A_{2}$ nunca teve esse interesse. Já, a professora $B_{1}$ mencionou que o interesse pela área de Educação Especial emergiu de questões familiares: "[...] porque na minha familia já tinha um com doença mental [...]".

A respeito da 'busca de conhecimentos sobre a Educação Especial durante a formação incial', o professor $A_{1}$ procurou, no Centro de Educação (UFSM), aprimorar seus conhecimentos nessa área: "[...] busquei junto com o Centro de Educação. Eu fiz algumas disciplinas da Educação Especial [...]". As professoras $A_{2}$ e $B_{1}$ relataram que não buscaram instrumentalização na formação inicial para trabalhar na área de Educação Especial.

Sobre a 'preparação para trabalhar em escolas de Educação Especial', o professor $A_{1}$ sentia-se preparado para atuar nesse tipo de escola, porque além dos cursos que foi realizando nessa área, também estagiou durante a graduação numa escola de Educação Especial. A professora $A_{2}$ não se sentia preparada, sendo que casualmente foi designada para atuar na 
escola de Educação Especial: "[...] eu fui trabalhar na escola do Estado, mas era em outra cidade e daí acabei vindo para cá, vim transferida [...]. [...] não me sentia preparada". Também a professora $B_{1}$ manifestou que não se sentia preparada para trabalhar em escola de Educação Especial.

Já, acerca do questionamento 'se ao longo da formação inicial alguns aspectos contribuíram para o trabalho nas escolas de Educação Especial', todos os professores $\left(A_{1} ; A_{2}\right.$ e $\left.B_{1}\right)$ relataram que na sua formação inicial não tiveram nenhuma disciplina que contribuísse para terem subsídios na atuação em escolas de Educação Especial, porém, o professor $A_{1}$ teve experiência como estagiário em uma escola de Educação Especial e, além disso, esse professor buscou disciplinas complementares e cursos que contribuissem em sua formação inicial na área de Educação Especial. Ao contrário disso, os professores $A_{2}$ e $B_{1}$ manifestaram que não tiveram nenhuma experiência desse tipo.

A respeito da formação de professores, García (1999) afirma que a formação inicial deve atender três funções: 1a) $O$ desenvolvimento e a experiência de futuros professores, de modo a assegurar uma preparação condizente com as funções profissionais que o professor deverá desempenhar; 2âa A função de controle de certificação ou permissão para poder exercer a profissão docente; e, $3^{3}$ ) A dupla função de ser, por um lado, agente de mudança do sistema educativo, mas, por outro, contribuir para a socialização e reprodução da cultura dominante.

Assim, ao considerarmos os depoimentos dos professores supracitados, podemos destacar que esses revelaram que não receberam uma formação inicial adequada para o seu fazer pedagógico em escolas de Educação Especial. Frente a esse quadro citamos Tedesco (1998) que afirma que a formação inicial do professor se apresenta de forma insuficiente e aligeirada, não sendo capaz de suprir os desafios da formação docente diante do novo contexto social atual que exige dos profissionais uma série de capacidades e habilidades que não estavam presentes nos cursos de formação até então.

Em relação ao curso de formação inicial dos professores $A_{1} ; A_{2}$ e $B_{1}$ (CEFD/UFSM), notamos que era baseado em currículo antigo (de 1990), onde ainda não possuía na grade uma disciplina específica de Educação Especial. Esse fato pode ser corroborado pelo estudo de Tavares e Krug (2003) que pesquisaram sobre se a Licenciatura em Educação Física do CEFD/UFSM (currículo de 1990) preparava seus acadêmicos para atuarem com alunos com deficiência, de forma inclusiva, na rede de ensino escolar. Nesse estudo os autores apontaram para a necessidade de uma atualização do currículo do CEFD/UFSM e sugeriram a criação de uma ou mais disciplinas que propiciassem aprendizados específicos para a atuação dos acadêmicos frente aos alunos com deficiência.

\subsection{Formação Continuada}

Nas últimas décadas, estudos sobre a formação inicial e continuada de professores, bem como sobre as práticas que envolvem a ação pedagógica do professor são exemplos da procura constante para compreender e melhorar cada vez mais a formação dos professores (FLORES, 2012).

A formação continuada de professores faz referência "a toda atividade realizada com uma finalidade formativa - tanto no desenvolvimento profissional como pessoal, individualmente ou em grupo - para um desempenho mais eficaz das suas tarefas atuais ou que o preparem para o desempenho de outras tarefas" (GARCíA, 1999, p.136).

Quando indagamos sobre a 'realização ou não de cursos, referentes à formação continuada', percebemos que os professores $A_{1}$ e $A_{2}$ não fazem mais cursos. Já a professora $B_{1}$ informou que realizou vários cursos: "de hidroterapia e Educação Especial". 
Os docentes também foram perguntados 'se costumavam investir na sua formação profissional' e os professores $A_{1}$ e $A_{2}$ afirmaram que não. $A$ professora $B_{1}$ relatou que costuma investir em cursos. Entretanto, parece-nos que houve uma contradição em alguns relatos, pois ao analisarmos as entrevistas percebemos que os professores $A_{1}$ e $A_{2}$ haviam afirmado que realizavam cursos quando oferecidos na escola. A professora $A_{2}$ afirmou que: "[...] a escola ofereceu. Acho que este ano. Era uma palestra assim sobre autoestima, relacionamento, muito boa e vieram dois palestrantes. [...]".

Já sobre 'se os cursos ajudam na qualidade das aulas' os professores $A_{1}$ e $A_{2}$ relataram que os cursos sempre auxiliam em algum aspecto. A professora $B_{1}$ foi mais enfática dizendo: "sim para cada vez mais melhorar", referindo-se a sua prática na escola.

Quando perguntados sobre 'o que entendiam a respeito de formação continuada', o professor $A_{1}$ respondeu que: "formação continuada é sempre estar buscando o conhecimento na área". A professora $\mathrm{A}_{2}$ colocou: "[...] eu entendo isso se atualizando [...]". Já a professora $\mathrm{B}_{1}$ falou que entende formação continuada como: "sempre se atualizando, aprendendo, estudando".

Acreditamos que a formação continuada deve atender às necessidades do ensino e às demandas dos professores, devendo ser buscados conhecimentos relacionados aos diferentes desejos e anseios, promovendo assim, o desenvolvimento de competências para melhorar a atuação docente.

Ainda foi perguntado aos professores 'se sentem vontade de investir em sua formação continuada'. Vale lembrar que o Governo Estadual oferece pouco incentivo financeiro, pois é preciso considerar que aqui no RS, o piso salarial nacional, que é direito de todos os professores do país, não é pago.

Considerando isto, percebemos que somente a professora $B_{1}$ investe na sua formação continuada na área de atuação de Educação Especial. Os outros dois professores $\left(A_{1}\right.$ e $\left.A_{2}\right)$ fazem os cursos que a escola oferece, porém não investem em outras estratégias para auxiliar as suas aulas na escola de Educação Especial.

Portanto, referindo-nos ao exposto anteriormente, o professor $A_{1}$ relatou: "[... não faço mais cursos depois que eu me separei (refere-se ao casamento). Devido à separação, tem um filho no meio, a atenção é toda para ele, não saí mais mesmo". E a professora $\mathrm{A}_{2}$ declarou: "não porque eu tô assim, eu gosto de trabalhar, gosto de ser professora, mas tô muito desiludida para investir em educação. Sabe, então, sinceramente, no momento não vale a pena tu investir. Procurar investir, eu realmente não tenho vontade [...]".

Entretanto, acreditamos que a formação continuada de professores, deve oportunizar elementos que, para que se compreendam as diferentes realidades escolares a partir de espaços formativos que vislumbrem atender as necessidades dos professores, procurando articular teoria-prática, pois entendemos que ambas não devem ser trabalhadas separadamente.

\subsection{Saberes Docentes}

Os saberes docentes influenciam a prática pedagógica do professor na escola (TARDIF, 2002). Nesse contexto, não temos a intenção de aprofundar os diferentes entendimentos de saberes docentes, mas argumentar como tais saberes influenciam na atuação dos professores de Educação Física nas escolas de Educação Especial.

Quando perguntamos aos professores 'se constroem saberes docentes na sua prática', obtivemos o seguinte: o professor $A_{1}$ precisou de uma breve explicação do que era 'saberes docentes', e logo após respondeu que "[...] depois que eu recebi a teoria foi diferente, tem a base da teoria para ir na prática, em cima disso tu reflete, toda tua mudança para ver se deu certo ou não $[\ldots]^{\prime \prime}$. 
A professora $A_{2}$ não respondeu adequadamente a pergunta. Na mesma questão a professora $\mathrm{B}_{1}$ declarou que: "na prática vivenciando e adaptando o que dava certo e errado e também lendo e estudando por livros".

Ao questionar os professores de 'como são desenvolvidas as características didáticopedagógicas das suas aulas' nas escolas de Educação Especial o professor $A_{1}$ enfatizou o seu planejamento: "[...] no início sondei eles para ver a clientela que eu tinha na mão e daí por diante vai embora [...]". A professora $A_{2}$ relatou que não faz mais planejamento: "[...] sabe como já faz tempo que eu trabalho as atividades vão fluindo". E a professora $\mathrm{B}_{1}$ manifestou: "faço plano de aulas anual, é também pela experiência".

Pelos relatos dos professores $\left(A_{1} ; A_{2}\right.$ e $\left.B_{1}\right)$ constatamos que não fazem o planejamento de cada aula ministrada, mas não quer dizer que os anos de experiência, substituem o planejamento. Conforme Libâneo (1994), o planejamento é uma atividade de reflexão acerca das nossas opções e ações e se não pensarmos detidamente sobre o rumo que devemos dar ao nosso trabalho, ficaremos entregues aos rumos estabelecidos pelos interesses dominantes na sociedade.

Ao questionarmos os entrevistados sobre 'quais os objetivos que são trabalhados nas aulas', o professor $A_{1}$ falou que: "mais a motricidade, mais este enfoque". A professora $A_{2}$ relatou que: "os pequenos eu trabalho em cima do que os professores me dizem dos alunos, eles precisam trabalhar equilíbrio, coordenação motora ou a noção de espaço e muita socialização. [...] e a noite é mais o lado da socialização. É que a gente trabalha mais jogos de mesa e trabalhamos o vôlei, alongamento [...] ping-pong até que a gente foi a Passo Fundo, teve disputas e todos trouxeram medalhas [...]".

Já a professora $\mathrm{B}_{1}$ citou que os objetivos para seus alunos são "a autoestima, e são globais como lateralidade, cooperação, equilíbrio concentração".

Assim, pelo relato dos professores, percebemos que os objetivos das aulas são baseados na Educação Psicomotora. Segundo Negrine (1995), a Educação Psicomotora é uma técnica, que através de exercícios e jogos adequados a cada faixa etária leva a criança ao desenvolvimento global do ser.

Ao perguntarmos aos professores sobre 'quais são os conteúdos desenvolvidos nas suas aulas', o professor $A_{1}$ relatou que: "[...] eu agora tô começando a aplicar futsal e voleibol de agosto/setembro para cá". A professora $\mathrm{A}_{2}$ manifestou que trabalha os conteúdos conforme os turnos: "os da tarde é conforme os professores e a noite é mais socialização, os jogos de mesa, ping-pong ou vôlei". E a professora $\mathrm{B}_{1}$ declarou que: "eu trabalho dança (tradicionais, folclóricas, flamengo, jazz)".

Acreditamos que os conteúdos ministrados pelos professores de Educação Física para os alunos com deficiência, atravessam a simples barreira de aprender isoladamente, pois trazem consigo uma bagagem de culturas de cada um, pois, segundo Freire (1999) os conteúdos, como conjunto de conceitos e formas culturais, cuja assimilação e apropriação pelos alunos são considerados essenciais para o desenvolvimento e a socialização.

Ainda procuramos saber dos entrevistados 'quais seriam os recursos de ensino utilizados durante as suas aulas'. Nessa questão o professor $A_{1}$ citou que: "uso aulas práticas, não uso audiovisual, só a prática, uso bastante material, pois a escola tem bastante material". A professora $\mathrm{A}_{2}$ manifestou que: "[...] à noite a gente tem a mesa de ping-pong no galpão, tem jogos de mesa, [...] tem bola, rede e à tarde, além disso, eu utilizo bambolês, corda, giz. Eu faço muitas brincadeiras antigas, assim faço muito circuito [...]". Já a professora $\mathrm{B}_{1}$ colocou que: "nas aulas é utilizado som, cd, roupas, panos". 
Nas aulas de Educação Física, é preciso usar diversos recursos para que os alunos desenvolvam um trabalho corporal, pois, segundo Soler (2003), nas aulas de Educação Física Escolar, podemos e devemos resgatar a manifestação cultural e dela nos apropriarmos, já que é muito útil no trabalho corporal. Esse trabalho corporal auxilia muito os alunos com deficiência.

Os professores relataram também 'como realizam as avaliações durante as suas aulas'. Nesse sentido, o professor $A_{1}$ citou que utiliza "mais a participação deles, como tem na proposta da escola é questão de valorização da participação na escola, autonomia deles na atividade [...]". A professora $\mathrm{A}_{2}$ citou que: "com pequenos é a participação [...] meu objetivo principal é que eles participem e que não briguem [...] de noite é a participação e também a socialização com os colegas [...]". Já a professora $\mathrm{B}_{1}$ afirmou que usa: "o acompanhamento dos alunos durante $o$ ano, sua evolução, também as apresentações deles, como foi a evolução".

De acordo com Luckesi (1996, p.33) a avaliação é "como um julgamento de valor sobre manifestações relevantes da realidade, tendo em vista uma tomada de decisão". Assim, com o relato dos professores $\left(A_{1} ; A_{2}\right.$ e $\left.B_{1}\right)$ percebemos que esses usam uma avaliação qualitativa dos alunos. Ainda Luckesi (1996, p.34) afirma que, a "atual prática da avaliação escolar estipulou como função o ato de avaliar a classificação, e não o diagnóstico, como deveria ser constitutivamente", ou seja, na avaliação destes professores é o desenvolvimento desses alunos que é levado em consideração.

Relativamente 'ao relacionamento com a direção da escola e com os colegas de profissão' os três professores (A1; A2 e B1) relataram que é muito bom. Segundo Alarcão $(2004$, p.35) o trabalho da direção da escola é um "desenvolvimento qualitativo da organização escolar e dos que nela realizam seu trabalho de estudar, ensinar ou apoiar a função educativa por meio de aprendizagens individuais e coletivas".

Uma questão à qual entendemos ser pertinente diz respeito à 'satisfação dos professores quanto à atuação nas escolas'. Obtivemos como resposta do professor $\mathrm{A}_{1}$ : "na prática sim eu me sinto muito bem, mas no restante dos turnos não, no turno da noite não, preferia estar bem mais na prática. Mesmo com 54 anos, com séries iniciais, com quinta, sexta série [...] mas é a quinta e sexta série passada, aí é meu chão ai é motricidade, para correr, fazer e eu vou à busca disso, tentar pegar estas 20 para uma escola à tarde que eu possa fazer, mesmo no final de carreira".

A professora $A_{2}$ colocou o seguinte: "olha, às vezes, eu acho que eu podia tá mais estimulada a dar aula, mas com os pequenos eu gosto muito de trabalhar porque eu vejo resultado, eles gostam de fazer, são ativos, à noite eu gostaria de fazer mais, só que assim eu me pego não posso exigir mais do que eles podem, trabalham o dia inteiro [...]".

Já a professora $\mathrm{B}_{1}$ afirmou: "gosto do que eu faço e adoro realizar os trabalhos com os alunos e também de ver o resultado".

Conforme os professores colocaram em suas entrevistas podemos perceber que estão satisfeitos com o 'ser professor'. De acordo com Silva e Krug (2010) as significações sobre a docência e sobre o professor são construídas muito antes de entrar numa sala de aula, pois temos uma representação do que seja um professor baseados nos saberes construídos ao longo de nossas histórias de vida, onde nossas experiências refletem comportamentos, valores, posturas profissionais e pessoais, que são os nossos primeiros saberes construídos sobre a docência.

Ao serem perguntados 'se as práticas anteriores como professores de Educação Física, contribuíram nos seus conhecimentos para as aulas' na escola de Educação Especial, o professor $\mathrm{A}_{1}$ falou que: "no decorrer da profissão, quando eu saí da Educação Especial e fui prá escola regular eu levei toda aquela bagagem de motricidade. Até a escola não entendeu direito sabe, porque a escola quer que o aluno jogue bola que acabe jogando bola [...]". A professora $\mathrm{A}_{2}$ 
manifestou o seguinte: "acho que sim, tudo ajuda desde que eu tinha de Educação Física das brincadeiras que fazia, eu trabalho muito tudo vai ajudando, tudo vai somando, tudo que é conhecimento [...]". Já a professora $\mathrm{B}_{1}$ respondeu que "os estágios na faculdade me ajudam para prática na escola".

Ao considerarmos estes depoimentos acreditamos que o processo de formação inicial destes professores teria que oferecer mais conhecimentos sobre a realidade do contexto escolar de alunos com deficiência. Nesse sentido, Teixeira e Teixeira (2009) afirmam que o contato com o contexto da inclusão torna-se um ponto positivo para o trabalho com alunos com deficiência, pois além de preparar os futuros professores, também oferece condições de um contato direto com a realidade escolar.

Já Malaco (2006) diz que a competência profissional envolve a capacidade do docente em articular os conhecimentos teóricos com a sua prática profissional, levando em conta as suas experiências profissionais e pessoais. Destaca que essa capacidade tem origem na formação inicial, sendo, posteriormente, ampliada com a formação continuada.

Assim, por meio dos relatos dos três professores $\left(A_{1} ; A_{2}\right.$ e $\left.B_{1}\right)$ constatamos que todos construíram saberes docentes na sua prática. Segundo Tardif $(2002$, p.31) "um professor é, antes de tudo, alguém que sabe alguma coisa e cuja função consiste em transmitir esse saber a outros". Esse saber denominado 'saber docente' é de grande importância para os professores atuarem e desenvolverem-se como tal.

Para Tardif (2002) entender a natureza dos saberes docentes, sua importância, como são adquiridos e qual a relação desses saberes com a prática docente são aspectos importantes para entender a formação e a prática do professor. O autor ressalta que o saber por si só não é suficiente, mas sim o saber ensinar.

Percebemos nesta pesquisa que o saber de cada um dos três docentes de Educação Física está relacionado com a sua identidade, com a experiência pessoal e profissional. De acordo com Tardif $(2002$, p.11), "[...] o saber dos professores é o saber deles e está relacionado com a pessoa e a identidade deles, com a sua experiência de vida e com a sua história profissional, com as suas relações com os alunos em sala de aula [...]".

O professor no contexto escolar nada mais é do que um agente de mudanças intelectuais e sociais dos seus alunos, e, de acordo com o autor supracitado os saberes docentes, "é um saber plural, formado pelo amálgama, mais ou menos coerentes de saberes oriundos da formação [...], de disciplinas e experiências" (TARDIF, 2002, p.36).

Desta maneira, o professor transforma-se no e pelo trabalho, sendo que o trabalho "modifica a identidade do trabalhador, pois trabalhar não é somente fazer alguma coisa, mas fazer alguma coisa de si mesmo consigo mesmo" (TARDIF, 2002, p.56). Assim, podemos notar que o professor está sujeito a inúmeras questões que podem interferir na sua atuação profissional e, portanto na construção de sua prática educativa.

Ainda segundo Tardif (2002, p.39) “o professor ideal é alguém que deve conhecer sua matéria sua disciplina e seu programa, além de possuir certos conhecimentos relativos às ciências da educação e à pedagogia e desenvolver um saber prático baseado em sua experiência cotidiana com os alunos".

No entanto, é imprescindível refletir e contextualizar tais saberes com o cotidiano escolar, para assim, compreender a importância que as experiências docentes carregam na construção da identidade profissional. A dificuldade de encarar o saber docente como algo que está em movimento no âmbito experimental volta-se para a não compreensão do cotidiano escolar como fonte de construção de conhecimento. A profissão professor apresenta no ambiente escolar uma das mais importantes tarefas, deve-se considerar os seus saberes construídos no âmbito de suas 
tarefas cotidianas. Contudo, as questões que perpassam as atuais conjunturas de formação profissional encontram uma considerável barreira, pois o professor de profissão é considerado um reprodutor do conhecimento desenvolvido pelos cientistas da educação (TARDIF, 2002).

A relação do saber docente com a sua origem e aplicação revelam uma dicotomia que atravessa o professor, onde a construção destes saberes é de responsabilidade única dos cientistas da educação e a sua aplicação e transmissão fica a cargo do professor da escola. Esta triste relação origina-se no momento em que os professores se limitam como detentores de saberes que não podem controlar (disciplinares e curriculares). Com isto, o professor não consegue associar os seus saberes escolares com a sua prática docente, justamente por não participar da construção e do controle destes saberes (TARDIF, 2002).

O presente dualismo anteriormente descrito, onde a teoria é construída longe da prática e esta não precisa de uma teoria norteadora, passa a perder espaço no instante em que percebemos que esta dicotomia é inexistente. Tardif (2002) coloca que a relação trabalhada é entre atores, sujeitos e saberes que se confluem e constroem os saberes pedagógicos e a prática profissional. Pimenta (2002) colabora para esse ponto de vista apontando que os saberes pedagógicos embasam e, são embasados pelas teorias, justamente porque elas são construídas a partir das vivências dos professores.

Pimenta (2002) ainda observa que os saberes pedagógicos parece sobrepor-se uns aos outros pela sua importância e esta ainda é classificada pela operacionalidade científica. Dessa forma, os saberes da experiência profissional são os que ganham menos destaque na formação de professores. Essa autora também afirma que a formação de professores não pode se restringir ao campo aplicado das ciências da educação, apontando como caminho a construção de saberes pedagógicos a partir das necessidades pedagógicas. O caminho emergente está em tomar como prática social educacional através da reinvenção dos saberes pedagógicos.

\section{CONSIDERAÇÕES FINAIS}

Ao tecermos considerações a cerca dos resultados analisados, percebemos que realmente a formação inicial dos entrevistados não ofereceu subsídios suficientes para a atuação dos professores de Educação Física lecionarem em escolas de Educação Especial. Como já observado no decorrer dessa pesquisa, o professor $A_{1}$ precisou matricular-se em disciplinas de cursos de Educação Especial para melhorar a sua formação inicial.

Com relação à formação continuada notamos que esta depende do investimento de cada professor, pois como podemos constatar os professores $A_{1}$ e $A_{2}$ não investem de maneira direta na sua formação continuada, somente quando a escola oferece cursos de alguma forma ambos estão se atualizando e melhorando a atuação nas suas aulas, e o professor $B_{1}$ sempre investiu e continua investindo na sua formação continuada.

Ainda percebemos que os professores vêm construindo os seus saberes por meio da prática diária, pois partiram dos conhecimentos prévios oriundos da teoria para posteriormente aplicá-los, verificando sua eficácia ou não. Isso, segundo os docentes, às vezes não dava certo, então era preciso encontrar um método que os auxiliasse durante as aulas, para conseguir desenvolver uma aula adequada para os alunos com deficiência.

É importante compreender que qualquer prática pedagógica anterior, mesmo não sendo com alunos com deficiência, auxilia no desenvolvimento das aulas, pois os conhecimentos são sempre partilhados, assim como os saberes pessoais, profissionais que estão incluídos desde a formação inicial até a formação continuada. Acreditamos que a busca pelo conhecimento, por meio de livros, de artigos, da experiência na própria profissão, da troca de conhecimento entre 
colegas, auxiliam na construção dos saberes docente de cada professor de Educação Física atuante em escolas de Educação Especial.

Ainda em relação à formação dos três professores de Educação Física entrevistados podemos apresentar uma perspectiva de autoformação, heteroformação e interformação. A autoformação é aquela em que o indivíduo participa de forma independente e tem o controle dos objetivos, processo, instrumentos e resultados do processo formativo. A heteroformação se organiza e se desenvolve por intermédio de especialistas, partindo de fora do sujeito. E a interformação é uma ação educativa que ocorre entre os futuros professores ou entre professores em fase de atualização, com a característica de troca, apoio pedagógico, podendo dizer-se que formam uma equipe de trabalho.

O que mais ficou saliente nesta pesquisa foi que os professores aprenderam com os seus saberes experienciais, que resultam do seu próprio exercício docente. Esses saberes são produzidos pelos professores por meio da vivência de situações específicas relacionadas ao espaço da escola e às relações estabelecidas com alunos e colegas de profissão. Nesse sentido, incorporam-se à experiência individual e coletiva sob a forma de habitus e de habilidades, de saber-fazer e de saber ser, pois a formação inicial foi insuficiente para a atuação nas escolas de Educação Especial.

\section{REFERÊNCIAS}

Alarcão, I. (2004). Do olhar supervisivo ao olhar sobre supervisão. In I. Alarcão. Supervisão pedagógica: princípios e práticas (pp.11-53). Campinas, SP: Papirus.

Barbin, L. (1977). Análise de conteúdo. Lisboa: Edições 70.

Bernardi, A. P., \& Krug, H. N. (2008). Saberes docentes e a organização didático-pedagógica da Educação Física na educação infantil. Revista Mackenzie de Educação Física e Esporte, 7(2), 85101.

Betti, M., \& Zuliani, L.R. (2002). Educação Física Escolar: uma proposta de diretrizes pedagógicas. Revista Mackenzie de Educação Física e Esporte, I(1) 73-81.

Lei n. 9.394, de 20 de dezembro de 1996. Lei de Diretrizes e Bases da Educação Nacional (1996). Brasil. Recuperado de https://www.planalto.gov.br/ccivil_03/Leis/L9394.htm

Candau, V. M. F. (1996). A formação continuada de professores: tendências atuais. In A. M. R. Reali \& M. G. N. Mizukami (Orgs.). Formação de professores: tendências atuais (pp. 139-152). São Carlos: EDUFSCar.

Caparroz, F. E. (2005). Entre a Educação Física na escola e a Educação Física da escola: a Educação Física como componente curricular. Campinas, SP: Autores Associados.

Carreiro da Costa, F. A. A. (1994). A formação de professores: objetivos, conteúdos e estratégias. Revista da Educação Física/UEM, 5(1), 26-39.

Cauduro, M. T. (Org.) (2004). Investigação em Educação Física e esportes: um novo olhar pela pesquisa qualitativa. Novo Hamburgo, RS: Feevale.

Flores, P. P. (2012). Formação inicial de professores de Educação Física: o Estágio Curricular Supervisionado em contexto escolar inclusivo (Monografia). Faculdade de Educação Física, UFSM, Santa Maria. 
Freire, P. (1999). Educação como prática da liberdade. Rio de Janeiro: Paz e Terra.

García, C. M. (1999). Formação de professores: para uma mudança educativa. Porto: Porto Editora.

Gil, A. C. (2010). Como elaborar projetos de pesquisa. São Paulo: Atlas.

Libâneo, J. C. (1994). Didática. São Paulo: Cortez.

Luckesi, C. C. (1996). Avaliação da aprendizagem escolar: estudos, proposições. 3. ed. São Paulo: Cortez.

Malaco, L. H. (2006). Formação de educadores: educação, currículo e competência profissional. Revista Unifieo, V(9), 57-60.

Marques, M. N. (2011). Caminhos e descaminhos da prática pedagógica em Educação Física Escolar (Dissertação de Mestrado). Faculdade de Educação, UFSM, Santa Maria.

Moreira, E. C. (2004). Educação Física Escolar: desafios e propostas. Jundiaí, SP: Fontoura.

Negrine, A. (1995). Aprendizagem e desenvolvimento infantil - psicomotricidade: alternativas pedagógicas. Porto Alegre: Prodil.

Pimenta, S. G. (2002). Saberes pedagógicos e atividades docentes. São Paulo: Cortez.

Silva, A. R., \& Krug, H. N. (2010). Aprendendo a ser professor: a dinâmica da trajetória formativa que tece as concepções da formação profissional na Educação Física. Revista Digital Lecturas: Educación Física y Deportes, 14(140), 1-6.

Silva, M. O. E. (2000). A análise de necessidades de formação na formação contínua de professores: uma análise para a integração escolar (Tese de Doutorado). Faculdade de Educação, USP, São Paulo.

Soler, R. (2003). Educação Física Escolar. Rio de Janeiro: Sprint.

Tardif, M. (2002). Saberes Docentes e formação profissional. Petrópolis, RJ: Vozes.

Tavares, J. E. B., \& Krug, H. N. (2003). Formação do profissional em Educação Física: um olhar para o processo de inclusão e inserção social. Revista Cadernos de Educação Especial, (21), 39-51.

Tedesco, J. C. (1998). O novo pacto educativo: educação, competitividade e cidadania na sociedade moderna. São Paulo: Ática.

Teixeira, D., \& Teixeira, R. T. S. (2009). Projetos de extensão: contribuições na formação inicial. Anais do Congresso Brasileiro de Ciências do Esporte. Salvador: Colégio Brasileiro de Ciências do Esporte. 